\title{
A Survey on the Methanol Content of Home Distilled Alcoholic Beverages in Transylvania (Romania)
}

\author{
Croitoru MD, Topor Elena, Fülöp Ibolya, Fogarasi Erzsébet \\ Department of Toxicology, Biopharmaceutics and Pharmacokinetics, University of Medicine and Pharmacy, Tîrgu Mureș, Romania
}

\begin{abstract}
Objective: Methanol appears in relatively high concentrations in alcoholic beverages obtained from fermented fruits distillates. These products are traditionally home made in many regions in Romania and other EU countries. The chronic use of products with high methanol concentration can be considered a health risk. The purpose of this work was to measure methanol concentration in a Romanian region where brandy-type alcoholic products are made from different fruits (plum, apple, pear, grapes), and to observe if there is a type of product that contains more methanol than the others.

Methods: The content of methanol in the tested alcoholic beverages was determined using a gas chromatographic method.

Results: Only $18 \%$ of the tested 56 samples met UE regulation regarding methanol content of alcoholic beverages $(0.4 \%$ in alcoholic drinks containing $40 \%$ ethanol). The highest concentration of $2.39 \%$ was found in a plum brandy. Plum brandies contained significantly higher amounts of methanol than brandies made from other fruits $(0.91 \mathrm{vs} 0.52 \%, p=0.01)$.

Conclusions: Home distilled alcoholic beverages obtained from fruits are a health threat due to their high methanol content. Strict regulations and tests should be introduced for such products.
\end{abstract}

Keywords: methanol, plum, grapes, orange, alcoholic beverages

Received: 15 February 2013

\section{Introduction}

Methanol is ubiquitously present in the human body and it also appears in human blood and breath [1]. It is produced by bacterial fermentation or by decomposition of pectins contained in fruits [2]. Bean, pea and lentil also contain ppm levels of methanol [3].

The decomposition of aspartame is another source of methanol in some beverages [4].

The presence of methanol in alcoholic beverages is a well known problem $[5,6]$. When fruits are fermented to obtain alcohol, methanol is also formed. In the process of distillation of fermented fruits, methanol is distilled together with ethanol due to their similar physicochemical properties. That is the reason why all alcoholic beverages obtained from fermented fruits will contain methanol. The European Union accepts a naturally occurring methanol concentration of $10 \mathrm{~g}$ methanol $\mathrm{l}^{-1}$ of ethanol in alcoholic beverages. This equates to $0.4 \%(\mathrm{v} / \mathrm{v})$ methanol in an alcoholic drink containing $40 \%$ alcohol [7]. The acceptable intake of methanol is higher when alcohol is present, since alcohol is an antidote of methanol poisoning.

Low levels of methanol are not considered toxic, but higher ingestion of this product can lead to serious health hazards, the most commonly known being blindness. Methanol is converted in the human body to formaldehyde, a toxic compound linked by some researchers with the diseases of civilization $[8,9]$.
Quantification of methanol in various matrices can be easily achieved using a gas chromatographic (GC) technique [10].

Home made alcoholic beverages (țuică, a type of brandy) that are never chemically analyzed are very common in Romania. They are traditionally made from fermented fruits, especially plums. The goal of this work was to analyze samples of such alcoholic beverages and to compare methanol concentrations with the EU regulations. Influence of type of fruit and sugar adding (in the fermentation process) on methanol concentration was assessed is order to see if it is possible to predict methanol concentration in such beverages.

\section{Methods}

\section{Equipment and reagents}

- Gas chromatograph GC-8A with FID detector, Shimadzu Corp., Japan;

- Column: Propach N, 1.2 m;

- Hydrogen 4.5, Linde Gas, Romania;

- Argon 4.7, Romsif Impex SRL, Romania;

- Methanol gradient grade, 99.9\%, Merck KgaA, Germany;

- Toluen GC quality, Merck KgaA, Germany;

- Ethanol for HPLC, Merck KgaA, Germany.

- Standard solution: $100 \mathrm{mg}$ methanol and 40\% ethanol solution to $10 \mathrm{ml} .10 \mu \mathrm{l}$ of standard solution was extracted with $1 \mathrm{ml}$ of GC quality toluene as described at 1.3. 


\section{Gas chromatograph settings}

- Column and FID temperature: $170^{\circ} \mathrm{C}$;

- Range: 1 ;

- Attenuation: 32;

- Injection volume $5 \mu$;

- Argon pressure: $2.5 \mathrm{~kg} \mathrm{~cm}^{-2}$;

- Hydrogen pressure: $0.5 \mathrm{~kg} \mathrm{~cm}^{-2}$;

- Air pressure: $0.5 \mathrm{~kg} \mathrm{~cm}^{-2}$.

\section{Sample preparation}

Samples were collected in $10 \mathrm{ml}$ vials and hermetically closed. Until analysis, samples were kept at $-20^{\circ} \mathrm{C}$.

A $10 \mu \mathrm{l}$ sample was introduced in an Eppendorf tube and $1 \mathrm{ml}$ of toluene was added, followed by stirring on a vortex mixer for 2 minutes. After 5 minutes, $5 \mu$ of toluene layer was injected into the GC equipment.

\section{Results}

\section{Performance of the GC technique}

Specificity: injection of alcoholic beverages obtained by grain fermentation (vodka) did not lead to formation of peaks with similar retention times with that of methanol $(\mathrm{RT}=0.83 \mathrm{~min})$. Method parameters ensured that a high resolution value is obtained for methanol and ethanol peaks. Figure 1 presents a typical chromatogram obtained for a $2 \%$ methanol concentration plum brandy. The only difference between chromatograms was the height of peaks 1, 3, and 4 .

Linearity: FID response increases linearly with the carbon content. Because of this reason we chose to compare the peak heights obtained in the samples with the peak height obtained in a methanol standard with a concentration of $1 \%$.

Recovery: a standard solution was prepared in a $40 \%$ alcoholic solution to mimick the chemical composition of alcoholic beverages, and was extracted exactly as the sam-

Table I. Concentrations of methanol in different types of alcoholic beverages

\begin{tabular}{lcccc}
\hline \multirow{2}{*}{ Type of fruit } & \multirow{2}{*}{$\begin{array}{c}\text { Added } \\
\text { sugar }\end{array}$} & \multicolumn{2}{c}{ Methanol concentration, \% } \\
\cline { 3 - 5 } & & Average & Min & Max \\
\hline Plum & No & $1.01(\mathrm{~N}=17)$ & 0.19 & 2.39 \\
Plum & Yes & $0.88(\mathrm{~N}=7)$ & 0.18 & 1.63 \\
Plum + apple & No & $0.51(\mathrm{~N}=5)$ & 0.27 & 0.96 \\
Plum + apple & Yes & $1.08(\mathrm{~N}=9)$ & 0.25 & 2.15 \\
Grapes & No & $0.52(\mathrm{~N}=4)$ & 0.16 & 1.28 \\
Apple & No & $0.49(\mathrm{~N}=3)$ & 0.25 & 0.78 \\
Pears & No & $0.41(\mathrm{~N}=2)$ & 0.39 & 0.44 \\
Plum + apple + cornel & No & $0.84(\mathrm{~N}=2)$ & 0.82 & 0.87 \\
Plum + apple + pears & No & $0.70(\mathrm{~N}=1)^{\star}$ & - & - \\
Plum + apple + pears & Yes & $0.41(\mathrm{~N}=1)$ & - & - \\
Cornel & Yes & $0.98(\mathrm{~N}=1)$ & - & - \\
Apples + mirobolam + apricot & No & $0.39(\mathrm{~N}=1)$ & - & - \\
Oranges + bananas & No & $0.68(\mathrm{~N}=1)$ & - & - \\
Oranges & No & $0.42(\mathrm{~N}=1)$ & - & - \\
Grains & No & $0.13(\mathrm{~N}=1)$ & - & - \\
\hline
\end{tabular}

*where only one sample was available no min and max values are applicable ples. This way no recovery correction is needed. However, in order to ensure that there is a reasonable value for recovery, a spiked sample of methanol free alcoholic beverage was compared with a standard obtained by dilution instead of extraction. A mean recovery value of $85.2 \%$ was obtained with a coefficient of correlation of $4.25 \%(\mathrm{~N}=5)$.

Detection and quantification limits: limit of detection is $15 \mathrm{mg} \mathrm{l}^{-1}$ and limit of quantification is $45 \mathrm{mg} \mathrm{l}^{-1}$. Limit of quantification is about 90 times lower than the EU limits for methanol in alcoholic beverages.

\section{Methanol concentration in tested beverages}

Fifty-six samples of home made brandies, obtained from Mureș, Covasna and Harghita counties in Romania were tested for the presence and concentration of methanol. Only 1 sample was obtained from grains, the others were obtained by different fruits or mixtures of fruits. Sugar was added sometimes to the fruits in order to increase ethanol concentration.

The samples were not externally contaminated with this solvent, since they were taken from rural areas where such solvent is not used.

Ethanol concentration of the samples ranged between $35-45 \%$. Table I summarizes the measured methanol concentrations. Plum and apple brandies were the most common among analyzed samples, since they are traditional products in the sampled areas. A low number of non-traditional brandies such as cornel, oranges and bananas were also available for analysis.

\section{Discussion}

As expected, only $18 \%$ of samples corresponded to European Union regulations regarding methanol concentration in alcoholic beverages. Papers published in the scientific literature [7] suggest that a concentration of $1 \%$ methanol can be considered safe, but only for a $100 \mathrm{ml}$ day $^{-1}$ consumption. Even if the accepted concentration is increased to $1 \%, 25 \%$ of the samples proved unsafe for human consumption.

The highest content of methanol was $2.39 \%$ in a plum brandy. Since the toxic methanol dose is between $0.3-1 \mathrm{ml}$

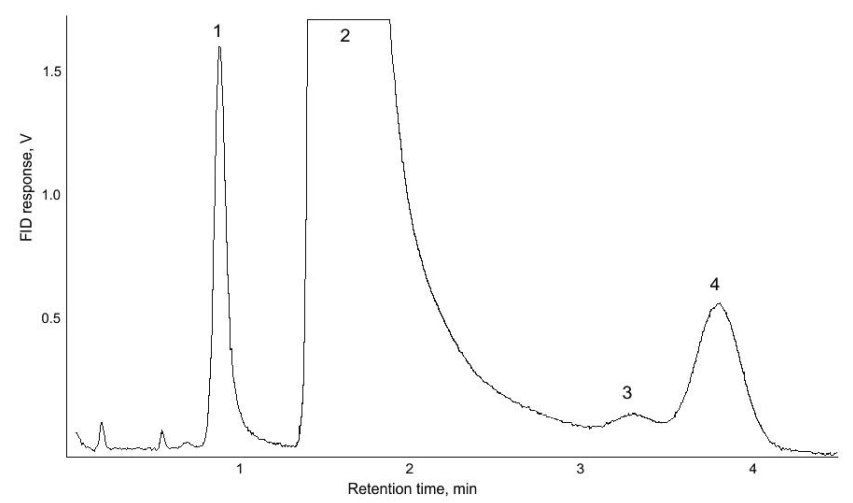

Fig. 1. A typical chromatogram obtained for a grape brandy, methanol concentration 1.28\% (1 - methanol, 2 - ethanol, 3 and 4 fruit fermentation related peaks, probably higher alcohols). 
$\mathrm{kg}^{-1}$ [11], a potentially lethal dose of methanol is contained in 11 of the mentioned brandy. Even if methanol toxicity is far less in the presence of ethanol, which inhibits its conversion to formaldehyde, the chronic use of these types of products can be considered a health risk. People with folate deficiency (pregnant women, elderly, alcoholics and people with poor quality diets) are especially exposed to this risk [11].

Since methanol concentration followed a normal (Gaussian) distribution, we used the unpaired two-tailed " $\mathrm{t}$ " test to check if fruit type significantly influences methanol content of alcoholic beverages. Results of the " $\mathrm{t}$ " test showed that plum brandies have an almost double methanol content than those who do not contain plums ( 0.52 vs $0.91 \% ; \mathrm{p}=0.01$ ).

It was expected that adding sugar would increase the ethanol to methanol ratio, since methanol formation from sugar fermentation is not yet described. Unexpectedly, adding sugar to fruits before the fermentation process did not significantly influence the methanol content of the final product.

\section{Conclusions}

Our results show that a significant contamination with methanol occurs during fermentation of fruits. Home made distillation will, almost every time, lead to a methanol content which is higher than the one accepted in the EU. When plum brandy is made, special care should be employed since this fruit forms high amounts of methanol.

Since methanol is converted in humans to formaldehyde, people consuming these products on a regular basis are prone to suffer effects of chronic formaldehyde exposure.

Because of the high amounts of methanol measured, we consider that all alcoholic beverages, including home made ones for personal use, should be tested for methanol content.

\section{References}

1. Qin T, Xu X, Polák T, Pacáková V, Stulík K, Jech L. A simple method for the trace determination of methanol, ethanol, acetone and pentane in human breath and in the ambient air by preconcentration on solid sorbents followed by gas chromatography. Talanta. 1997;44:1683-1690.

2. Lindinger W, Taucher J, Jordan A, Hansel A, Vogel W. Endogenous production of methanol after the consumption of fruit. Alcohol Clin Exp Res. 1997;21:939-943.

3. Fisher GS, Lovegren NV, Legendre MG, Schuller WH - Volatile constituents of dried legumes. J Agric Food Chem.1979;27:851-853.

4. Portari GV, Mathias MGM, Almeida BB, Marchini JS, Jordao AA. Effect of the temperature and $\mathrm{pH}$ on methanol release in coffee brew sweetened with aspartame. Acta Aliment Hung. 2009;38:303-307.

5. Hou CY, Lin YS, Wang YT, et al. Addition of phenolic acids on the reduction of methanol content in wine. J Food Sci. 2008;73:C432-437.

6. Hang YD, Woodams EE. Influence of apple cultivar and juice pasteurization on hard cider and eau-de-vie methanol content. Bioresour Technol. 2010;101:1396-1398.

7. Paine A, Davan AD. Defining a tolerable concentration of methanol in alcoholic drinks. Hum Exp Toxicol. 2001;20:563-568.

8. Chung TN, Kim SW, Park YS, Park I. Unilateral blindness with third cranial nerve palsy and abnormal enhancement of extraocular muscles on magnetic resonance imaging of orbit after the ingestion of methanol. Emerg Med J. 2010;27:409-410.

9. Monte WC. Methanol: a chemical Trojan horse as the root of the inscrutable. U Med Hypotheses. 2010;74:493-496.

10. Phillips M, Greenberg J. Detection of endogenous ethanol and other compounds in the breath by gas chromatography with on-column concentration of sample. Anal Biochem. 1987;163:165-169.

11. ${ }^{* \star *}$ http://www.inchem.org/documents/hsg/hsg/v105hsg.htm, accessed on 01.2011 